\title{
Justice Beyond the State: Social Practices and Relational Equality
}

\author{
Justiça para além do Estado: práticas sociais e igualdade relacional
}

10.21680/1983-2109.2021v28n57ID25552

\author{
Vitor Sommavilla de Souza Barros \\ Universidade Federal da Paraíba (UFPB) \\ 0000-0003-2968-4357 \\ vitorsommavilla@gmail.com
}

\begin{abstract}
In this paper, I argue that principles of justice, contrary to what John Rawls and Thomas Nagel believe, do apply transnationally. I start with a debate about the proper scope of justice and defend the view according to which social practices, apart from the structure of the state, ought to be included in the purview of justice. However, I hold that there is no need to include individual behaviour, alongside social practices, opposing G. A. Cohen's view on this matter and agreeing with Aaron James. I then argue for a relational account of equality, understood as a central principle of justice, whose application is feasible at the transnational level. Finally, I briefly discuss two examples of international social practices that could (and in my view ought to) be assessed in terms of social justice and respond to two objections to my position.
\end{abstract}

Key words: transnational justice; relational equality; social practices; basic structure.

Resumo: Neste artigo, argumento, contra as posições de John Rawls e Thomas Nagel, que princípios de justiça se aplicam ao nível transnacional. Inicio com um debate acerca do escopo adequado da justiça e defendo a visão segundo a qual práticas sociais para além da estrutura do estado devem ser incluídas no âmbito da justiça. No entanto, eu sustento que não há necessidade de que o comportamento individual também seja incluído, ao lado das práticas sociais. Neste ponto, portanto, oponho-me à posição de G.A. Cohen e sigo o entendimento de Aaron James. Em seguida, defendo a concepção da igualdade relacional, compreendendo a igualdade como um princípio de justiça central, cuja aplicação ao nível transnacional é possível. Por fim, discuto brevemente dois exemplos de práticas sociais internacionais que podem (e, na minha visão, devem) ser avaliadas segundo os termos da justiça social e respondo a duas objeções à minha posição.

Palavras-chave: justiça transnacional; igualdade relacional; práticas sociais; estrutura básica.

\section{INTRODUCTION}

It is hard to overestimate the impact John Rawls's masterpiece, $A$ Theory of Justice (1999b; first published in 1971), caused in the community of moral and political philosophers. It provided a whole new research programme for the 
subsequent generations. While many attempted to understand the theory contained in the book and its consequences if implemented, many others tried to expand Rawls's insights into areas he had not explicitly dealt with. This is very clearly the case with the theoretical debate about global justice. Rawls had overtly limited his philosophical considerations to a closed democratic society. However, drawing particularly on the second part of his conception of justice as fairness, namely, the difference principle, authors like Charles Beitz (1979) and Thomas Pogge (1989) virtually created a new philosophical subject: global justice. Seeing the potential that the difference principle, and Rawlsian political philosophy as a whole, had in understanding and combating injustices and poverty at the global level, Beitz and Pogge enthusiastically expanded Rawls's insights beyond their teacher's intent.

Nevertheless, Rawls didn't share their enthusiasm. Nor did they make him change his mind after their first works were published. In his next major book, Political Liberalism, Rawls reaffirms the restriction of his analysis to the closed society (2005, p. 12; first published in 1993). What is worse, when he finally dedicated himself to the philosophical analysis of the global level, he did so in terms of a law of peoples, that is, in terms of principles that regulate relations between peoples. These peoples would internally determine their principles of social justice and then, in a second moment, they would come up with principles for international proper coexistence. Crucially, there is no space here for what cosmopolitans such as Pogge wanted, that is, principles of social justice for citizens at the global level. Members of different peoples aren't parties in a same enduring political structure, so social justice wouldn't apply to them collectively. They relate to each other as members of different nations and international justice is to be thought of solely as a set of principles guiding the relations between nations or peoples (Rawls, 1999a).

If Rawls's book, The Law of Peoples, led to a great deal of disillusionment about cosmopolitan ideals for global justice among mainstream liberal political philosophy, Thomas Nagel's much-debated article The Problem of Global Justice painted an even darker picture. According to him, the existence of a sovereign coercive power - the state - that governs over its citizens is a necessary precondition for concerns about social justice to be justifiable. Since we don't have a world government, global social justice, apart from humanitarian duties to assist those in calamitous situations, doesn't exist as well. In his words, "the requirements of justice themselves do not [...] apply to the world as a whole, unless and until, as a result of historical developments not required by justice, 
the world comes to be governed by a unified sovereign power" (2005, p. 121). The notion of coercion is particularly important for Nagel. ${ }^{1}$ For him, the more robust claims for social justice that we are justified to make as citizens of a state derive from the coercive nature of the state, particularly the idea that membership is not an option for its citizens. However, we are not parties in any such coercive relation alongside citizens from other countries. Therefore, there is no reason to oblige me to promote or respect a principle of social justice in relation to a foreigner. $^{2}$

Nagel's article provoked a number of reactions and criticism. ${ }^{3}$ In fact, in the following pages, I will try to develop an alternative reaction to Nagel's understanding that social justice doesn't apply at the global level. There are two fundamental theses that I wish to support. The first one is that there is no reason to suppose that social justice relates solely to the coercive structure of modern states. My intention, therefore, is to argue contra Nagel and say that social justice applies more broadly to social institutions and practices, among which the state is one - probably the most important - but not the only one. This is a point about the proper scope of justice. My second point is about the content of the concept of justice. I will argue that a primary principle for social justice is equality, which I will understand, following Elizabeth Anderson, as relational equality. Bringing these two theses together, the third and last section will present the idea that equality is a valuable and viable principle to be promoted in social institutions that operate transnationally. I will briefly consider examples of such a transnational institution or practice that are not characterised by the coercive nature of the state and in which a principle of equality could and, in my view, ought to be implemented. Those examples - those of trade and migration - notwithstanding, the greater aim of this essay is not to point to existing transnational institutions that are not primarily subject to the state-centric logic and, therefore, prove Nagel's state-centric view wrong. This is a task for empirical research. The aim of this essay in political philosophy is to make the theoretical claim that social justice is associated with meaningful social practices, be they related to the coercive state or not. This is sufficient to remove the blockage that Nagel put on the way of those willing to assess transnational practices with the lenses of social justice. I also present a viable criterion for the

\footnotetext{
${ }^{1}$ On this, see also Blake (2001), to whom Nagel is admittedly indebted in his discussion.

${ }^{2} \mathrm{He}$ focuses on equality: "the only universal requirement of equality is conditional in form: We are required to accord equal status to anyone with whom we are joined in a strong and coercively imposed political community. [...] An institution that one has no choice about joining must offer terms of membership that meet a higher standard [of equality]" (Nagel, 2005, p. 133).

${ }^{3}$ Cohen \& Sobel (2006) and Julius (2008) are two important critical responses.
} 
assessment of transnational social justice, namely, relational equality. Finally, at the end of the third section, I consider two possible objections to my position and attempt to respond to them.

\section{THE SUBJECT OF JUSTICE}

G. A. Cohen wrote a famous article in the 1990's criticizing Rawls, among other things, for being unclear as to what he meant with the expression "basic structure of society" (Cohen 1997). This is, of course, a very serious charge, since the basic structure is for Rawls "the primary subject of justice". Furthermore, justice is simply the most important concept in Rawls's philosophy, so that determining what are we talking about when we speak of justice or, more precisely, what is it that we are primarily interested in analysing with the notion of justice is of paramount importance. Rawls's definition is as follows:

For us the primary subject of justice is the basic structure, or more exactly, the way in which the major social institutions distribute fundamental rights and duties and determine the division of advantages from social cooperation. By major institutions I understand the political constitution and the principal economic and social arrangements. Thus the legal protection of freedom of thought and liberty of conscience, competitive markets, private property in the means of production, and the monogamous family are examples of major social institutions. Taken together as one scheme, the major institutions define men's rights and duties and influence their life prospects, what they can expect to be and how well they can hope to do. The basic structure is the primary subject of justice because its effects are so profound and present from the start. (Rawls, 1999b, p. 6). ${ }^{4}$

There are fundamentally two points that Cohen wants to make in his critique of Rawls's description of the basic structure. The first one, already mentioned, is that Rawls is unclear. What exactly are these "major social institutions", of which Rawls provides but a set of examples? Are they solely the coercive structure of the state? The seemingly unwarranted introduction, without further reasoning, of "the monogamous family" suggests otherwise. In fact, incorporating important contributions by feminist thinkers, Cohen argues that the family, which is not part of the coercive structure of the state, nevertheless "influences significantly men's and women's life prospects" and, indeed, "its effects are very profound and present from the start". Cohen, therefore, takes side with the feminists, who criticize Rawls for failing to incorporate appropriately into his theory a fundamental social institution that is a major site of injustices in most societies. Crucially, these injustices obtain despite frequently not being endorsed by the state's legal structure. The family

\footnotetext{
${ }^{4}$ See also Political Liberalism (2005, p. 11 and Lecture VII, pp. 257-88).
} 
constitutes a fundamental institution in determining people's life prospects, independently of the justice or injustice of legal state institutions. This is what he called the substance of their critique. ${ }^{5}$

However, once the door for non-coercive institutions is open, Cohen argues that not only the family plays this important role, but many other social practices also do. At this point, Cohen presents the second fundamental thesis in his paper, namely, that individual choice should also be included in the scope of social justice. In his view, this is the form of the feminist critique and its most relevant theoretical contribution. ${ }^{6}$ Cohen sees the introduction of individual action into the scope of justice as a necessary consequence of the inclusion of non-coercive social practices:

But once the line is crossed, from coercive ordering to the non-coercive ordering of society by rules and conventions of accepted practice, then the ambit of justice can no longer exclude chosen behavior, since the usages which constitute informal structure (think, again, of the family) are bound up with the customary actions of people. (Cohen, 1997, p. 20)

The basic argument underlying the inclusion of individual action here is that, in order for informal non-coercive social practices and institutions to be just, it is necessary not only that the structure itself, with its principles, ideals and standards, be just; it is also required that the action of those taking part in the practice be just. Hence his adoption of the feminist motto "the personal is political"7. Because they are non-coercive, these informal practices, despite having profound impact on one's life prospects, require individual action and choice to sustain them. ${ }^{8}$

I agree with Cohen that a great many social practices are crucial for determining one's life prospects, several of which are not part of the coercive structure of the state. Therefore, the scope of social justice really needs to be

\footnotetext{
5 "The substance of the feminist critique is that standard liberal theory of justice, and the theory of Rawls in particular, unjustifiably ignore an unjust division of labor, and unjust power relations, within families (whose legal structure may show no sexism at all). That is the key point of the feminist critique, from a political point of view." (Cohen, 1997, p. 4).

6 "But the (often merely implicit) form of the feminist critique, which we get when we abstract from its gendercentered content, is that choices not regulated by the law fall within the primary purview of justice, and that is the key lesson of the critique, from a theoretical point of view." (Cohen, 1997, p. 4)

${ }^{7}$ This way we also understand the final form of his critique of Rawls: "Rawls is in a dilemma. For he must either admit application of the principles of justice to (legally optional) social practices, and, indeed, to patterns of personal choice that are not legally prescribed, both because they are the substance of those practices, and because they are similarly profound in effect, in which case the restriction of justice to structure, in any sense, collapses; or, if he restricts his concern to the coercive structure only, then he saddles himself with a purely arbitrary delineation of his subject matter.” (Cohen, 1997, pp. 21-2)

${ }^{8}$ Summing up his position, Cohen says: "Informal structure is not a behavioral pattern, but a set of rules, yet the two are so closely related that, so one might say, they are merely categorially different. Accordingly, so I argued, to include (as one must) informal structure within the basic structure is to countenance behavior, too, as a primary subject of judgments of justice." (Cohen, 1997, p. 29)
} 
amplified to incorporate these other institutions. ${ }^{9}$ However, I wish to contest the idea that individual action and choice have to be brought alongside informal practices into the purview of justice. This is precisely the critique made by Aaron James of Cohen's philosophy. Like me, James agreed with Cohen that many practices beyond the state ought to be included in the ambit of justice, but he convincingly argued that individual action is not required to maintain informal institutions. His crucial passage reads as follows:

Cohen doubts that we can distinguish principled appraisal of a practice from principled appraisal of particular actions, because any practice exists only because of its supportive actions. While it is quite true that for any practice there is a set of actions whose non-performance means that the practice would not have existed, there is nevertheless a crucial difference between the total set of acts that realize a practice, whose absence means that the practice would not exist, and, a given act whose absence wouldn't undermine the practice, because the widespread compliance of others is sufficient to sustain it (James, 2005, pp. 35-6).

The idea, with which I fully agree, is that saying that individual action is important to the sustainment of social institutions doesn't mean that it should be included in the scope of justice, because it is perfectly consistent to think of an individual's non-compliance with principles of the institution of which she is a member and, at the same, to think of the healthy perpetuation of this very same institution. Truly, if all individuals were to disrespect, at the same time, some fundamental principle of a given institution, then this would probably amount to the dissolution of the institution. But individual action doesn't need to be included in the scope of justice because parties have reason to expect that other parties to the same institution (or most of them) will comply.

James puts a great deal of emphasis on the notion of justification. For him, justification is the key to assessing whether a practice is just or unjust. Social justice or injustice is always a feature of social practices, not of individual actions, and what reveals an injustice is the fact that a practice is not (no longer) justifiable to its members. It is not really relevant whether a given person actually acts according to the agreed terms defining a social practice. The important part is that these terms are regarded by all members as justifiable, so that the distribution of roles, rights and duties is seen as just (James, 2005, pp. 37-8). I subscribe to James's position on this.

\section{RELATIONAL EQUALITY}

\footnotetext{
${ }^{9}$ I use the terms social practices and social institutions interchangeably, of which state structures are one subset among others.
} 
In this section, I want to step back a little from considerations about the scope of justice and say some things about the appropriate content of the concept of justice. Having mentioned the idea of justifiability, I now want to explore what does it take to be able to demand a justification from the social practice in which one takes part, given that this justification is an integral part to the assessment of this social practice in terms of social justice. Roughly put, I argue that to be in a position to demand justification means to stand as equal in relation to other parties in the social practice under scrutiny. That is the idea I develop next.

The debate about equality in the last few years has been polarised between luck and relational egalitarians. In fact, Elizabeth Anderson (1999), a relational egalitarian, coined the term luck egalitarianism to refer to her theoretical opponents. By this she meant a group of authors, predominant in the debate about equality by the time she was writing, who focus on arbitrary material inequalities. Their basic point is that people should not be penalised for circumstances that are beyond their control. People should benefit or suffer the consequences of the options they made, including what turns out retrospectively in the future to have been bad decisions. However, they should not be in a position of material advantage or disadvantage merely because of luck or fortune. The fundamental purpose of social justice is then, in this overly simplified version of luck egalitarianism that I am sketching, to correct the unjust distribution of benefits and burdens of social cooperation, by redistributing the resources of the arbitrarily better off. ${ }^{10}$

Anderson, in my opinion correctly, claims that luck egalitarians are missing the point of equality. They fail to see what is really at stake in the struggle for social justice and equality in the actual history of social movements and oppressed minorities. Luck egalitarians have a narrow focus on the secondary topic of resource distribution, which doesn't primarily concern the oppressed segments of society. What these oppressed groups first and foremost fight for isn't for a bigger share of the total amount of wealth available in society. What they aspire to is that the relations in which they stand with other members of society cease to be oppressive. This is what inequality fundamentally means, that is, a relation that is characterised by the oppression or domination of some party (parties) over other parties to that relation. Hence, equality and inequality are, properly understood, features of relations. A relation is equal when their members stand as equal to each other and treat each other with equal concern and respect.

\footnotetext{
${ }^{10}$ See also Scheffler (2005) and Anderson (2010).
} 
Under these conditions of equality, the terms of cooperation, agreed on by the members themselves, can be seen as justifiable. Likewise, as equals, all members have an equal say in the regulative evolution of the practice or institution or relation to which they are party. ${ }^{11}$ Fighting inequality is primarily about effecting institutional change, so that the relations that take place within the institution cease to be unequal, that is, oppressive. Fighting inequality does not mean redistributing arbitrarily owned resources, as a mere redistribution of resources very often doesn't amount to a suppression of existing oppressions and dominations. To use an example, an oppressed person would hardly feel that justice has been made if she receives a cheque from the oppressor, but the oppression doesn't cease to exist.

Of course, this is not to say that relational egalitarians should not care about distribution at all. On the contrary, as Christian Schemmel (2011) has persuasively argued, relational egalitarians have strong intrinsic as well as instrumental reasons to consider resource distribution a valuable political goal. The case for the intrinsic value of distribution from a relational egalitarian point of view is less obvious and would lead to discussions that are beyond the scope of this essay. But the case for the instrumental value of distribution can be made with less complexity.

The ultimate goal for relational egalitarians is always the establishment of institutions characterized by the absence of oppression and domination. This means that social justice is always the ultimate purpose. However, it is not inconsistent to think that, as a tool for policy makers whenever they are designing the best strategy to attack a given social (relational) inequality, distribution figures as the best alternative. Think about the importance given by many feminists to wives having their own source of income, so that they are not subject to their husbands' domination and oppression. It might be the case that, in certain situations, redistributing income or wealth is the best way to tackle this problem. As long as it is done with the clear purpose of eliminating relational inequality, distribution is a valuable tool for policy-makers. This leads to my second point about distribution, namely, that it should be undertaken (whenever it's proven to be the best alternative) up to a level of sufficiency. This means that material inequalities ought to be reduced only until the point in which the

\footnotetext{
${ }^{11}$ In Anderson's words: "Positively, egalitarians seek a social order in which persons stand in relations of equality. They seek to live together in a democratic community, as opposed to a hierarchical one. Democracy is here understood as collective self-determination by means of open discussion among equals, in accordance with rules acceptable to all." (1999, p. 313)
} 
remaining (if any) material inequalities become irrelevant to determining whether a given relation or social practice is just or unjust. ${ }^{12}$

\section{TRANSNATIONAL JUSTICE AND EQUALITY}

At this point, I already argued about the scope of justice from a formal, a priori perspective, and established, or so I hope, that there is no necessary connection between state structure and social justice. Being so, all significant social practices qualify as appropriate subjects of social justice. As I will suggest ahead, this applies both to domestic and transnational practices. I also characterized one particular feature of the content of the concept of justice, the notion of equality understood as relational equality. The highlight given to equality is justified both by its centrality and by the fact that it is a principle that can be adequately applied at the global level. ${ }^{13}$ At least, this is my contention. In this final section, I will briefly present some examples, in order to build my case for the application of equality as a principle of social justice to transnational practices. I will then assess two possible objections or limitations of my position. I hope the view comes out stronger from these confrontations.

One important example of a transnational social practice is that of trade. Despite being subject to governmental interference or influence throughout, one could say that transnational trade has a life of its own. It is an enduring - and highly relevant for its parties - social practice that ought to be considered under the rubric of social justice. ${ }^{14}$

Consider an enduring relation between private parties, such as that obtaining between a transnational company, say, a mining company, and individuals in the country in which the mining activities occur. These enterprises last many years, decades, and deeply change the life prospects of those involved. I think that concerns of social justice apply here. Beyond what is determined by international law as well as by the domestic law of both the country of origin of

\footnotetext{
${ }^{12}$ Harry Frankfurt introduced the notion of sufficiency in the debate about equality. He argued that the literature mistakenly focused on equality, while what really mattered was not whether all persons had the same, but whether they had enough. However, having enough for him meant having enough to fulfill one's life's projects and reasonable ambitions and, therefore, is related to welfare as the appropriate currency for the debate. Hence the meaning I give to sufficiency differs substantially from what Frankfurt meant. Cf. Frankfurt (1987). For an influential critique of Frankfurt on this, see Casal (2007).

${ }^{13}$ For this reason, I don't quite follow Thomas Pogge's account of global justice. Although, like me, he proposes a conception of social (and global) justice whose subject are social institutions, and not individual behaviour, he doesn't ground his account of global justice on relational equality. Rather, he seeks to identify a criterion for global justice in terms of human rights. See his (Pogge 2002). I thank an anonymous reviewer for referring to Pogge's work in this context.

${ }^{14}$ In fact, trade is Aaron James's paradigmatic case at the global level, to which he applies the concept of fairness to assess it in terms of social justice (James, 2012).
} 
the company (and of some of its employees, let's suppose) and the country were the activities take place, there is a relation that is established among all persons involved in this long-lasting project that has sufficient impact in their lives to be included in the scope of justice. All persons taking part in this enterprise should be put in a place of equal standing and consideration and all points of view must be taken into consideration while assessing whether the practices are just or unjust. This is not the case of an isolated exchange; it is rather an enduring social practice, that therefore gives rise to justified claims about the nature of its guiding principles.

Another example is that of migration. Take particularly the case of secondgeneration legal immigrants. They are often citizens of the country that hosts them, but quite frequently remain attached to people (relatives or acquaintances) in their country of origin. They often entertain robust relations with these people, relations that shape their experiences of the world, their ambitions and life prospects. They visit relatives and friends as much as they can (or else they are reprimanded), people in both countries express views about how and what others ought to eat, about how the religious practices should be conducted, and so on. There is no reason not to consider theses relations and practices ${ }^{15}$ as social institutions that have major impact on people's lives, despite being transnational. They are, I contend, part of the proper scope of justice.

I acknowledge that these examples might be question begging. I don't claim that they are not. They merely illustrate what I mean by transnational social institutions, and don't have to effectively exist in the described form. Really important for the purposes of this article was to establish the possibility that such practices exist and, when existing, that they should be analysed in terms of social justice and equality. This theoretical claim I take to be correct, against Nagel's contention. The dissociation of social justice from the coercive institutions of the state has played the biggest role in making this point. I now proceed to the consideration of a few objections to applying the theory I'm defending to the global level.

Someone might be willing to say that, despite acknowledging that transnational social institutions have or could have real purchase on people's lives, relations within the state and, especially, relations that form part of the coercive structure of the state are much more relevant. In this sense, whenever a

\footnotetext{
${ }^{15}$ I sometimes use the terms 'relations' and 'practices' interchangeably. More precisely, social practices are stable sets of social relations, to the point of gaining some independence from particular instances of relations. Relations within such social practices, I contend, should be included within the purview of social justice.
} 
conflict would emerge, citizens would be compelled to side with their fellow citizens, because among these there is a much stronger net of interdependence, cooperation, law enforcement, and so on. This might be true. I believe in some very specific cases it isn't, but I will not argue for it here. My point is merely to recall that these conflicts occur all the time, and not only when coercive or transnational institutions are at stake. Suppose, for instance, I am a member of both a tennis society and of my family, both being strong social practices, enduring in time and influencing its members' life prospects. Now assume further that both hold occasional meetings as part of their rules of membership, though unwritten these rules might be. However, sometimes meetings coincide in the same day and I have to decide for one of them. Suppose further that I usually decide for the family, as its meetings are less frequent but more charged with meaning, such as birthdays and Christmas. Nevertheless, by doing this, I don't reject the tennis association or render its rules and principles void. It is just a fact of life that most of us take part in several institutions simultaneously and sometimes have to miss some of its rituals or favour some other institution. This doesn't nullify them, as I (and other members) will eventually opt for them, under other circumstances.

The same reasoning applies to transnational practices: saying that citizens are usually willing to favour their fellow citizens whenever there is a clash makes nothing in the direction of supressing their relevance. To put it directly, the point is that there is nothing intrinsically peculiar about my fellow countrymen, except that we are parties to the same social institution that happens to be the strongest of all social institutions in the Modern World, the state. ${ }^{16} \mathrm{It}$ is the strongest because it has more influence on most persons' life prospects. It is, however, a matter of intensity or degree, and not of nature, that distinguishes the state from other social institutions, at least for the purposes of assessing social justice.

A final objection comes from the worry about cultural relativism. Someone could very well argue that the principles of justice I am advancing reveal Western liberal values. This person would continue to say that there is no guarantee that the best treatment to someone who doesn't share these liberal values is, for example, to implement the principle of relational equality in our relations with her. Indeed, it is reasonable to assume that the idea of moral equality between persons is a peculiarly Modern and liberal concern. As Charles Larmore has convincingly argued, the notion of equal respect between persons of equal

\footnotetext{
${ }^{16}$ See Robert E. Goodin's piece on this (1988).
} 
standing is fundamental to the self-understanding of Western Modern societies; it constitutes, in his words, "the moral we" the we are. ${ }^{17}$

I accept this restriction to the liberal moral project and acknowledge that other cultures might not endorse it. However, I still believe that equality is a valuable principle in our relations with people from these other cultures. First, there is prima facie reason to believe that they will not be willing to be treated as less than equal. The same applies to us, evidently, so this raises the chances of equality being accepted as a guiding principle. Second, if there is a conflict and the people from these other cultures irreversibly regard equality as something that should be rejected, than an egalitarian, unless obliged to, should not take part in this particular transnational social institution. Nothing determines that persons should engage in all social practices they are able to. On the contrary, we should make choices according to our preferences, values and principles, when circumstances allow - as we in fact already do.

\section{CONCLUSION}

I will limit myself to a brief restatement of my case: the proper subject of justice are meaningful, enduring and life-shaping social practices, be they domestic or transnational. As for the content of justice, equality, understood as relational equality, ought to figure prominently. Relational equality accords very well with the history of movements fighting oppression, with the need for justification in social practices and with the challenges of establishing principles for justice for transnational social institutions. Evidently, many aspects of the issues discussed above demand more detailed investigation. Despite these limitations, however, I believe the idea of relational equality applied to transnational institutions could make a relevant contribution to the more and more pressing debate on global justice.

\section{REFERENCES}

ANDERSON, Elizabeth. What is the Point of Equality? Ethics, Vol. 109, No. 2, 1999, pp. $287-337$

\footnotetext{
${ }^{17}$ See this passage: "To respect them as ends, as persons whose reason is of equal moment with our own, is by contrast to impose on them only those principles whose grounds they too can appreciate. This idea of respect may seem so evident that we barely notice the way it frames our thinking. Yet it defines the moral "we" that we are. And however much it may for us go without saying, to hold that the rules of political society must accord with the reason of its members is not a deliverance of reason itself. It represents a contingent development, one quite alien to other cultures of the past and of the present too, for which the crucial demand on any political form of life is, for instance, that it be pleasing to God." (Larmore, 2008, p. 13)
} 
. The Fundamental Disagreement between Luck Egalitarians and Relational Egalitarians. Canadian Journal of Philosophy, 40, sup1, 2010, pp. 1-23

BEITZ, Charles. Political Theory and International Relations. Princeton, NJ: Princeton University Press, 1979

BLAKE, Michael. Distributive Justice, State Coercion, and Autonomy. Philosophy \& Public Affairs, 30, 2001, pp. 257-296

CASAL, Paula. Why Sufficiency Is Not Enough. Ethics, Vol. 117, No. 2, 2007, pp. 296-326 COHEN, G. A. Where the Action Is: On the Site of Distributive Justice. Philosophy \& Public Affairs, 26, 1997, pp. 3-30

COHEN, Joshua and SABEL, Charles. Extra Rempublicam Nulla Justitia? Philosophy \& Public Affairs, Vol. 34 no. 2, 2006, pp. 147-175

FRANKFURT, Harry. Equality as a Moral Ideal. Ethics, Vol. 98, No. 1, 1987, pp. 21-43

GOODIN, Robert E. What is so Special about Our Fellow Countrymen. Ethics, Vol. 98, No. 4, 1988, pp. 663-686

JAMES, Aaron. Power in Social Organization as the Subject of Justice. Pacific Philosophical Quarterly, 86, 2005, pp. 25-49

Fairness in Practice: A Social Contract for a Global Economy. New York:

Oxford University Press, 2012

JULIUS, A. J. Nagel's Atlas. Philosophy \& Public Affairs, 34, 2006, pp. 176-192

LARMORE, Charles. The Autonomy of Morality. Cambridge: Cambridge University Press, 2008.

NAGEL, Thomas. The Problem of Global Justice. Philosophy \& Public Affairs, 33, 2005, pp. 113-147

POGGE, Thomas W. Realizing Rawls. Ithaca, NY, Cornell University Press, 1989

POGGE, Thomas W. World Povery and Human Rights: Cosmopolitan Responsibilities and Reforms. Cambridge, UK: Polity Press, 2000

RAWLS, John. The Law of Peoples, with 'The Idea of Public Reason Revisited'. Cambridge, MA: Harvard University Press, 1999a

. A Theory of Justice. Revised edition. Cambridge, MA: Harvard University Press, 1999b

Political Liberalism. Expanded edition. New York: Columbia University Press, 2005

SCHEFFLER, Samuel. Choice, circumstance, and the value of equality. Politics Philosophy Economics, 4: 5, 2005, pp. 5-28

SCHEMMEL, Christian. Why Relational Egalitarians Should Care About Distributions. Social Theory and Practice, Vol. 37, No. 3, 2011, pp. 365-90 